\title{
DIAGNÓSTICO DA QUALIDADE DE MAÇÃS NO MERCADO VAREJISTA BRASILEIRO ${ }^{1}$
}

\author{
LUIZ CARLOS ARGENTA², MARCELO JOSÉ VIEIRA ${ }^{3}$, FRANCIELLE DE SOUZA ${ }^{4}$, \\ WALTER SÉRGIO PINTO PEREIRA ${ }^{5}$, FERNANDO KAZUHIRO EDAGI ${ }^{6}$
}

RESUMO - Este estudo foi realizado para analisar a qualidade e o preço de maçãs no mercado varejista brasileiro. Amostras de maçãs cv. Gala, Fuji e Red Delicious foram coletadas mensalmente entre março de 2010 e janeiro de 2011, em 20 supermercados de Curitiba, São Paulo, Belo Horizonte, Rio de Janeiro e Recife. Quatro supermercados de cada cidade foram previamente selecionados e definidos como locais de amostragem das maçãs ao longo dos 11 meses. A Categoria (escala 1 para máxima qualidade a 3 para mínima qualidade) das maçãs foi determinada pela análise da qualidade externa (coloração, severidade de danos fisiológicos, mecânicos, por fungos, insetos, granizo, etc.) de acordo com normas legais do MAPA. A categoria média das maçãs expostas nos supermercados aumentou ao longo do ano de 1,6 a 2,0 para 'Gala', de 1,8 a 2,4 para 'Fuji' e de 1,4 a 1,8 para 'Red Delicious'. A perda da qualidade dos frutos no período, entre as datas de empacotamento e de exposição aos consumidores, foi evidente em todos os meses e cultivares. A depreciada qualidade externa das maçãs expostas nos supermercados foi associada a altas incidências de danos mecânicos e podridões, que variaram de 13 a $50 \%$ e 1 a 20\%, respectivamente, dependendo da cultivar e do mês de análise. A firmeza da polpa das maçãs diminuiu de março a julho para níveis inferiores a $12 \mathrm{lb}$ e então tendeu a aumentar a patamares de aproximadamente $14 \mathrm{a} 15 \mathrm{lb}$ de novembro a janeiro, dependendo da cultivar. Variações dos preços e da qualidade ao longo do ano indicaram que o preço das maçãs nas gôndolas dos mercados é mais influenciado pela sazonalidade ou pressão de oferta que pela qualidade das maçãs. $O$ preço das maçãs variou entre as regiões de comercialização de forma similar para as três cultivares. Dados evidenciam que o tempo médio entre a data de embalagem dos frutos e sua exposição nas gôndolas dos mercados é de 17 e 28 dias para maçãs 'Gala' e 'Fuji', respectivamente.

Termos para indexação: dano mecânico, pós-colheita, distúrbios fisiológicos.

\section{APPLE QUALITY DIAGNOSIS IN THE BRAZILIANRETAILER MARKET}

ABSTRACT - The aim of this study was to evaluate the quality and price of apples in the Brazilian retailer market. Samples of Gala, Fuji and Red Delicious apples were collected monthly between March of 2010 and January of 2011 in 20 supermarkets in Curitiba, São Paulo, Belo Horizonte, Rio de Janeiro and Recife. Four supermarkets in each city were previously selected and defined as sources of apple samples for the 11 months of the study. The Category (scale 1 to 3 ) of the apples was defined by external fruit quality (color; severity of physiological, mechanical, fungus, insect and hail damage, etc) according to the legal standards of MAPA. Category 1 and 3 represent the highest and lowest fruit quality standards, respectively. The average Category of the apples in the supermarkets increased during the year from 1.6 to 2.0 for 'Gala', from 1.8 to 2.4 for 'Fuji' and from 1.4 to 1.8 for 'Red Delicious'. The loss of quality in the period between the packing and the exposure of the fruits in the supermarket was evident in all 11 months and varieties. The decrease of the external quality in the apples at the supermarket was associated with high incidence of mechanical damages and decay that ranged between 13 to $50 \%$ and 1 to $20 \%$, respectively, depending of the variety and the month of evaluation. The flesh firmness of the apples decreased between March and July for levels below $12 \mathrm{lb}$ and tended to increase to levels close to 14 and $15 \mathrm{lb}$ between November and January depending of the variety. The standards of price and quality fluctuation along the year indicate that the retail price of the apple is more influenced by the seasonality or the pressure of sales than by the quality of the fruit. The variation of apple prices among regions was similar for the three varieties. Data indicated that average period between packing and supermarket exposure is 17 and 28 days for 'Gala' and 'Fuji' apples, respectively.

Index terms: mechanical damage, postharvest, physiological damage.

\footnotetext{
${ }^{1}$ (Trabalho 047-14). Recebido em: 13-02-2014. Aceito para publicação em; 11-11-2014.

${ }^{2}$ Eng. Agr., D.Sc., Estação Experimental de Caçador, Epagri, Caçador-SC. E-mail: argenta@epagri.sc.gov.br

${ }^{3}$ Eng. Agr., M.Sc., Centro de Ciências Agroveterinárias, UDESC, Lages-SC. E-mail; marvieira@gmail.com

${ }^{4}$ Eng. Agr., M.Sc., AgroFresh, Fraiburgo, SC. E-mail: fdesouza@agrofresh.com

${ }^{5}$ Eng. Agr., M.Sc., WP Agro Business Consultoria, Piracicaba-SP. E-mail: wsppereira@yahoo.com.br

${ }^{6}$ Eng. Agr., M.Sc., AgroFresh, Davis, California-USA. E-mail: FEdagi@agrofresh.com
} 


\section{INTRODUÇ̃̃O}

A produção brasileira de maçãs aumentou em mais de um milhão de toneladas nos últimos 35 anos. Nos últimos quatro anos, a produção brasileira de maçãs variou de aproximadamente um milhão a um milhão e duzentas mil toneladas, sendo aproximadamente $60,0 \%$ de 'Gala', 30,0\% de 'Fuji' e $10,0 \%$ de outras cultivares (PETRI et al., 2011). O destino das maçãs brasileiras produzidas nos últimos anos tem sido o consumo in natura interno $(67,6 \%)$, consumo in natura externo (7\%) e industrialização para produção de suco e outros alimentos $(25,4 \%)$ (ABPM, comunicação pessoal).

A qualidade das maçãs produzidas no Brasil também aumentou expressivamente nas últimas décadas. Esse aumento da qualidade deve-se primeiramente pelo plantio de novas variedades, mutações coloridas de 'Gala' e 'Fuji'. Adicionalmente, o uso de porta-enxertos anão, os novos métodos aprimorados de manejo de pomares, a colheita dos frutos em estádio de maturação mais adequado e os métodos aprimorados de armazenagem e de controle da ação do etileno têm promovido aumento considerável da qualidade das maçãs brasileiras comercializadas in natura. Melhoria da qualidade das maçãs brasileiras ofertadas no mercado também ocorreu pela implementação do regulamento técnico de identidade e qualidade de maçãs empacotadas no Brasil (Instrução Normativa $\mathrm{n}^{\circ} 5$ do Ministério da Agricultura Pecuária e Abastecimento - MAPA) (BRASIL, 2006).

Infelizmente, a melhoria da qualidade das maçãs brasileiras ofertadas não tem resultado em majoração proporcional do retorno financeiro aos produtores e à 'indústria' de maçãs, devido primeiramente ao aumento dos custos de produção ocorrida nas últimas décadas (PÉRÈS, 2009). No entanto, parece inquestionável o papel da qualidade para a manutenção ou o aumento do consumo per capita de frutas frescas. Aparentemente, a demanda por frutas frescas, incluindo maçãs, continuará expandindo no Brasil, nos próximos anos, devido ao crescimento populacional e de sua renda.

A expansão da oferta e da diversidade de frutas frescas e de alimentos industrializados (lanches) parece favorecer o aumento da exigência dos mercados e dos consumidores por qualidade. A disposição dos consumidores a pagar maior preço por frutas de maior qualidade tem sido demonstrada (GALLARDO et al., 2011). A escolha de frutos pelos consumidores baseia-se inicialmente na aparência externa, sobretudo na coloração da epiderme, mas a repetição da compra pode ser retraída quando as expectativas dos consumidores pela qualidade interna (referentes ao sabor, textura, ausência de distúrbios, etc.) dos frutos não são atendidas (HARKER et al., 2003; 2008; ZEEBROECK et al., 2007). Segundo Batt e Sadler (1998), a resposta dos consumidores à compra de maçãs de baixa qualidade varia, entre outras coisas, com a redução do retorno à compra de maçã, troca de cultivar e/ou substituição de maçã por outra espécie de fruta. Pesquisa recente da Confederação Nacional da Agricultura (CNA, 2011) evidencia que aproximadamente $60 \%$ dos consumidores brasileiros se dispõem a substituir o consumo de frutas por outros alimentos, tais como laticínios, produtos de padaria e guloseimas quando a qualidade e/ou os preços se distanciam de suas expectativas.

Mais de $90 \%$ das maçãs brasileiras são colhidas nos meses de janeiro a abril, em pomares localizados nos Estados de Santa Catarina e Rio Grande do Sul (PÉRÈS, 2009). Isso significa que antes de chegar aos consumidores, a maior parte das maçãs é armazenada por um a dez meses e transportadas a longas distâncias do local de produção.

Aproximadamente $80 \%$ das frutas e verduras in natura são comercializadas aos consumidores em supermercados e o restante em feiras de ruas, lojas de frutas e verduras ('sacolões'), etc. (CNA, 2011), indicando que os supermercados são locais apropriados para estudos sobre 'qualidade no mercado' e padrões de consumo de maçãs.

O presente trabalho foi realizado para avaliar a qualidade de maçãs nos supermercados brasileiros em função do mês e explorar possíveis relações entre qualidade, preço e região de consumo.

\section{MATERIAL E MÉTODOS}

Amostras de maçãs das cultivares 'Gala' e seus clones, 'Fuji' e seus clones e 'Red Delicious' foram coletadas mensalmente a partir de março de 2010 até janeiro de 2011, em 20 supermercados localizados nas seguintes cidades (5): Curitiba (PR), São Paulo (SP), Belo Horizonte (MG), Rio de Janeiro (RJ) e Recife (PE).

Os vinte supermercados foram selecionados antecipadamente, em fevereiro de 2010. Selecionaramse, em cada cidade, dois supermercados de rede nacional e dois supermercados de rede regional do respectivo Estado. Os frutos foram amostrados sempre nos mesmos supermercados, ao longo dos 11 meses, na quarta semana de cada mês. Amostras de 22 frutos por cultivar (3) foram coletadas ao acaso nas gôndolas de cada supermercado (4) e cidade (5), 
nos 11 meses, exceto para 'Gala', que não foram amostradas no mês de janeiro. Os 14.080 frutos amostrados ao longo dos 11 meses foram analisados no mesmo dia da amostragem, na respectiva cidade. Todas as amostragens e análises dos frutos foram realizadas por um único técnico treinado $\left(E^{2} g^{a}\right.$. Agrônoma), o qual viajou mensalmente para as cinco cidades.

Os frutos foram analisados individualmente quanto à qualidade interna e externa. A qualidade interna foi determinada pela análise da firmeza de polpa, teor de açúcares solúveis e distúrbios fisiológicos, patológicos ou por insetos. A qualidade externa foi avaliada determinando-se a percentagem de cor vermelha e severidade dos seguintes defeitos na superfície: distúrbios fisiológicos (murcha, escaldadura superficial, senescência, danos por deficiências minerais, etc.), distúrbios patológicos (podridões, lesões por doença pré-colheita, etc.), danos por insetos, danos por fatores abióticos (ex: granizo, geada, toxidez química, danos mecânicos, etc.) e defeitos morfológicos. A presença dos defeitos externos foi determinada para cada fruto. Os dados de qualidade externa foram usados para determinar a categoria de cada fruto, seguindo o regulamento técnico de identidade e de qualidade de maçãs (Instrução Normativa n ${ }^{\circ} 5$ do Ministério da Agricultura) (BRASIL, 2006). Dessa forma, os frutos foram qualificados como Categoria 1 (qualidade máxima), Categoria 2 ou Categoria 3 (qualidade mínima).

Nas gôndolas, determinou-se a temperatura do ar e da polpa de uma maçã por cultivar e anotaram-se os nomes das cultivares, dos preços de venda anunciados e a forma de exposição dos frutos. Quando autorizado por representantes dos supermercados, determinou-se a temperatura da sala de estocagem de frutas e verduras, e analisaram-se as embalagens de maçãs correspondentes aos lotes de maçãs expostas nas gôndolas. Anotaram-se a data de empacotamento, a variedade, o calibre (tamanho) e a categoria descritos nos rótulos das caixas. Esses dados das embalagens de maçãs encontradas nas salas de estocagem de frutas e verduras foram coletados em aproximadamente $55 \%$ das visitas aos supermercados.

Os preços médios de venda realizados pelos produtores em 2010 e 2011 foram informados pela Associação Brasileira dos Produtores de Maçãs (ABPM, comunicação pessoal).

A firmeza de polpa foi medida, após remoção da epiderme, em dois lados opostos da região equatorial de cada fruto, utilizando-se de um penetrômetro manual com ponteira de $11 \mathrm{~mm}$ de diâmetro. Uma amostra de suco $(\sim 0,2 \mathrm{~mL})$ foi extraída de uma fatia longitudinal externa de cada maçã para análises do teor de sólidos solúveis (SS). O teor de SS do suco foi determinado com um refratômetro digital (Atago, Japão). A incidência (\%) de frutos com distúrbios internos e defeitos externos foi determinada pela contagem dos frutos com sintomas em relação ao número total de frutos da amostra. Nas análises de firmeza de polpa, dano mecânico e distúrbios fisiológicos, foram utilizadas, para cada amostra, 22 repetições, sendo cada repetição composta por um fruto. Para a determinação do teor de SS, para cada amostra, foram utilizadas cinco repetições, compostas de quatro frutos.

Foi utilizada uma amostra contendo 22 repetições (cada repetição constituída por um fruto) nas análises da qualidade interna e externa dos frutos para cada combinação de cidade, supermercado, cultivar e mês. Os dados foram submetidos à análise da variância (ANOVA), e a diferença entre os tratamentos (Cultivar e Região), determinada pelo teste de Tukey $(p<0,05)$. A condição de normalidade dos dados foi verificada por meio do teste Shapiro-Wilk (W). O coeficiente de correlação e sua significância entre as variáveis estudadas foram determinadas por meio do teste Pearson ProductMoment $(\mathrm{p}<0,05)$. Os dados foram analisados utilizando o programa SAS.

\section{RESULTADOS E DISCUSSÃO}

\section{Qualidade Interna:}

A firmeza da polpa das maçãs expostas nos supermercados diminuiu continuamente de março a julho para níveis inferiores a $12 \mathrm{lb}$ e então tendeu a aumentar a patamares de aproximadamente $14 \mathrm{lb}$ para 'Gala' e 15 lb para 'Fuji' e 'Red Delicious' (Figura 1). A redução da firmeza da polpa ao longo do ano foi mais acentuada em maçãs 'Fuji' e 'Red Delicious' do que em maçãs 'Gala'. A menor amplitude de firmeza da polpa verificada em maçãs 'Gala' ao longo do ano deve-se ao fato de que, em março, a firmeza da polpa desta cultivar já estava baixa.

Este comportamento de redução e de aumento da firmeza de polpa gerando janelas de baixa firmeza da polpa não é surpreendente e pode estar relacionado às logísticas de colheita e classificação dos frutos. Em função do grande volume de frutos a serem colhidos em curto espaço de tempo, parte da produção é inevitavelmente colhida em estádio avançado de maturação, inapropriado para armazenagem por médios ou longos períodos. Desequilíbrios entre oferta e demanda e, eventualmente, limitações da capacidade de classificação e empacotamento fazem 
com que parte dos frutos colhidos sobre maduros sejam armazenados por períodos superiores ao seu potencial.

O aumento da firmeza da polpa a partir de agosto, possivelmente, está relacionado à oferta de frutos colhidos precocemente, em estádios ideais de maturação para máxima conservação pós-colheita, e ao emprego de tecnologias avançadas de conservação, incluindo atmosfera controlada e controle do etileno pelo 1-MCP (1-metilciclopropeno).

Estudos de Harker et al. (2008) indicam que a firmeza da polpa de maçãs deve ser superior a 14 libras para máxima aceitação pelos consumidores. Importante notar que a firmeza da polpa média das maçãs 'Gala' foi igual ou inferior a $14 \mathrm{lb}$ ao longo de todo o período de análises, março a dezembro. Assumindo que a variação da firmeza da polpa entre frutos de cada amostra siga uma Distribuição Normal (W>0,95), mais de $50 \%$ das maçãs 'Gala' ofertadas nos mercados estudados apresentavam firmeza da polpa inferior a $14 \mathrm{lb}$ ao longo de todo o ano (Figura 1). Considerando que a variação da firmeza da polpa média entre supermercados também seguiu Distribuição Normal (W>0,95), mais de 50\% das amostras de maçãs 'Gala' ofertadas nos mercados estudados, apresentavam firmeza média inferior a $14 \mathrm{lb}$ ao longo de todo o ano. Esses dados indicam que a maior parte das maçãs da cv. Gala ofertada no mercado apresenta firmeza da polpa inferior àquela de maior aceitação pelos consumidores.

A menor firmeza da polpa não resulta apenas em menor apreciação sensorial pelos consumidores. Maçãs com menor firmeza da polpa normalmente apresentam maior incidência de escurecimento da polpa e são mais vulneráveis a danos mecânicos e podridões (ZEEBROECK et al., 2007; MITSUHASHI-GONZALEZ et al., 2010). Os resultados do presente estudo evidenciam maior incidência de escurecimento da polpa de maçãs 'Galas' no mês de menor firmeza da polpa, em julho (Figuras 1 e 4). Adicionalmente, a firmeza da polpa de maçãs 'Gala' dos 20 supermercados correlacionou-se negativamente com a incidência média de escurecimento da polpa nos meses de julho $(\mathrm{r}=-0,46 ; \mathrm{p}<0,05)$ e outubro, $(\mathrm{r}=-0,64 ; \mathrm{p}<0,05)$. A firmeza da polpa média de maçãs 'Fuji' foi superior a $14 \mathrm{lb}$ durante a maior parte dos meses estudados. Exceção ocorreu nos meses de julho, setembro e outubro, quando maçãs 'Fuji' apresentaram firmeza da polpa média inferior a $14 \mathrm{lb}$ (Figura 1). De maneira geral, maçãs 'Fuji' exibem menor perda de firmeza da polpa durante a armazenagem que maçãs 'Gala' (ARGENTA; DENARDI, 1994). Mesmo assim, maçãs 'Fuji' podem ser rejeitadas pelos consumidores devido ao desenvolvimento de sabor e odor diferente do padrão característico da cultivar, após longos períodos de armazenagem, sobretudo quando os frutos apresentam menor firmeza da polpa (VARELA et al., 2005). A firmeza da polpa média de maçãs 'Red Delicious' também foi inferior a $14 \mathrm{lb}$ na maioria dos meses ao longo do ano, sendo mínima em julho, assim como observado para maçãs 'Gala' (Figura 1).

O Regulamento Técnico de Identidade e Qualidade de Maçãs (Instrução Normativa $n^{\circ}$ 5) determina que, para serem comercializadas, as maçãs 'Gala' e 'Red Delicious' devem apresentar firmeza da polpa superior a $9 \mathrm{lb}$, enquanto as maçãs 'Fuji' devem apresentar firmeza da polpa superior a $10 \mathrm{lb}$ (BRASIL., 2006). Considerando a variabilidade de firmeza da polpa média entre supermercados e entre os frutos, verifica-se que parte das maçãs 'Gala', especialmente aquelas disponíveis nos mercados entre junho e julho, apresentava firmeza da polpa inferior ao limite determinado pela norma (Figura 1). Apesar de as maçãs analisadas neste estudo, frequentemente, apresentarem firmeza da polpa superior ao limite mínimo tolerado pela Instrução Normativa $\mathrm{n}^{\circ} 5$ (BRASIL., 2006), o tema padrões mínimos de qualidade de maçãs expedidas para o mercado deve ser continuadamente debatido pelo setor produtivo em resposta ao crescente aumento da produção nacional de frutas, ao aumento das exigências dos mercados e aos estudos que indicam preferência dos consumidores por maçãs com firmeza da polpa igual ou superior a $14 \mathrm{lb}$ (HARKER et al., 2008).

O presente estudo identificou que o conteúdo médio de sólidos solúveis (SS) nas maçãs expostas nos supermercados foi superior a $12 \%$, para as três cultivares estudadas, em todos os meses analisados (Figura 1). Exceção ocorreu para a 'Gala' em abril, quando o conteúdo médio de SS foi inferior a $12 \%$. No entanto, medidas da variabilidade (desvio- padrão) entre os supermercados revelam que os teores de sólidos solúveis de maçãs 'Gala' também foram inferiores a $12 \%$ para amostras de alguns supermercados nos meses de março e de setembro a dezembro. Os índices de preferências dos consumidores por maçãs correlacionam-se positivamente com o teor de SS (HARKER et al., 2008), sendo a rejeição de maçãs por baixo teor de SS máxima quando inferior a $12 \%$ (HARKER et al., 2002). A grande maioria dos consumidores prefere maçãs com alta firmeza da polpa e altos teores de SS, embora alguns prefiram alta relação SS/acidez, enquanto outros prefiram baixa relação SS/acidez (HARKER et al., 2008). 


\section{Qualidade externa:}

Maçãs são classificadas, durante o empacotamento, por categorias (CAT 1, CAT 2 e CAT 3) seguindo o Regulamento Técnico de Identidade e Qualidade de Maçãs (BRASIL, 2006). Essa classificação baseia-se em aspectos estéticos externos, tais como coloração e ocorrência de distúrbios ou defeitos de formação.

A categoria média das maçãs 'Gala' coletadas nas gôndolas dos supermercados variou de 1,6 (máxima qualidade) a 2,0 (mínima qualidade) ao longo do ano (Figura 2). A categoria de maçãs 'Fuji' coletadas nos supermercados foi semelhante às de 'Gala' para vários meses, exceto para o mês de novembro, quando a categoria média das maçãs 'Gala' ofertadas nos supermercados foi inferior (maior qualidade) à de 'Fuji' $(\mathrm{p}<0,05)$ (Figura 2; Tabela 1). A categoria de maçãs 'Red Delicious', nas gôndolas, variou menos que as categorias de maçãs 'Gala' e 'Fuji', permanecendo entre 1,4 e 1,8 ao longo do ano (Figura 2). Maçãs Red Delicious dispostas nos mercados brasileiros são importadas de outros países. A análise das embalagens de maçãs nas salas de armazenagem dos supermercados evidenciou que $100 \%$ das maçãs 'Red Delicious' expedidas ao mercado brasileiro eram CAT 1, com exceção dos meses de março e abril. Essa análise das embalagens também comprovou que maçãs nacionais 'Gala' e 'Fuji' das três categorias (CAT 1, CAT 2 e CAT 3) são expedidas ao mercado brasileiro. Mesmo assim, a categoria de maçãs 'Red Delicious', na gôndola, não diferiu estatisticamente $(\mathrm{p}<0,05)$ da categoria de maçãs 'Gala' ao longo do ano, mas foram menores (melhor qualidade) em relação a maçãs 'Fuji' nos meses de março, maio, outubro, novembro e janeiro (Tabela 1).

Em aproximadamente $56 \%$ das visitas aos supermercados onde foram coletadas as amostras de maçãs, foi possível identificar a embalagem (origem) dos frutos expostos na gôndola. Isso permitiu comparar a categoria dos frutos expostos no ponto de comercialização e a categoria dos frutos no momento da expedição, no local de empacotamento. Os resultados indicam que há perda significativa da qualidade (aumento da categoria) entre o ponto de expedição das maçãs, nos parques de classificação e empacotamento, e o momento de exposição comercial aos consumidores. Essa perda de qualidade pós-empacotamento foi evidente para as três cultivares, ao longo de todo o ano, exceto para 'Gala', que ocorreu principalmente no $2^{\circ}$ semestre do ano (Figura 2).

A depreciação da qualidade (aumento da categoria) das maçãs das três cultivares analisadas, após o empacotamento, foi associada ao elevado índice de dano mecânico (Figura 3). A incidência de maçãs com danos mecânicos nas amostras analisadas variou de 13 a 50\%, dependendo da cultivar e da época de análise, sendo que a maior incidência foi observada em agosto, com destaque para a cultivar Red Delicious (50\%), seguida pelas cultivares Gala e Fuji (45\%). A correlação entre dano mecânico e a categoria das maçãs foi significativa para as cultivares Gala $(r=0,49 ; p<0,05)$, Fuji $(r=0,36 ; p<0,05)$ e Red Delicious $(\mathrm{r}=0,63 ; \mathrm{p}<0,05)$. Resultados das análises de correlação também indicaram que a ocorrência de danos mecânicos foi associada negativamente à firmeza da polpa dos frutos para as cultivares Gala $(\mathrm{r}=-0,35 ; \mathrm{p}<0,05)$, Fuji $(\mathrm{r}=-0,45 ; \mathrm{p}<0,05)$ e Red Delicious $(\mathrm{r}=-0,41 ; \mathrm{p}<0,05)$, assim como descrito em estudos anteriores (MITSUHASHI-GONZALEZ et al., 2010).

O dano mecânico caracteriza-se pela deformação da superfície dos frutos, sem rompimento a olho nu visível da epiderme, provocado por batidas, vibrações e compressão dos frutos em diferentes etapas da colheita ao empacotamento e da expedição a partir dos parques de armazenagem, classificação e empacotamento até a exposição aos consumidores, nos supermercados. A ocorrência de dano mecânico deprecia a aparência externa dos frutos e aumenta o risco de contaminação por fungos e bactérias quando há indução de microrrachaduras da epiderme (ZEEBROECK et al., 2007).

O Regulamento Técnico de Identidade e Qualidade de Maçãs (BRASIL, 2006) prevê tolerância a danos mecânicos de até $1 \mathrm{~cm}^{2}, 2$ $\mathrm{cm}^{2}$ e $5 \mathrm{~cm}^{2}$ para maçãs CAT 1 , CAT 2 e CAT 3 , respectivamente. Assumindo que as empresas empacotadoras estejam seguindo as normas legais de classificação, pode inferir-se que a maior parte dos danos mecânicos descritos no presente estudo resulta de práticas inapropriadas de carregamento, descarregamento, transporte e manuseio das maçãs nos entrepostos e nos supermercados. Destacam-se o transporte não refrigerado a longa distância por estradas mal pavimentadas, o descarregamento e o empilhamento manual das caixas nos entrepostos e nos supermercados, o descarregamento a granel dos frutos nas gôndolas por operadores dos supermercados, o manuseio irregular pelos consumidores ao escolher os frutos nas gôndolas, etc. Frequentemente, a altura de empilhamento de caixas nos caminhões e nos entrepostos de comercialização do atacado, excede à recomendação dos fabricantes das embalagens, resultando em rompimento da coluna das embalagens e em compressão das frutas das camadas inferiores. 
Parece evidente que diferentes empresas ou agentes da cadeia de suprimento operam de forma desuniforme quanto a medidas para a preservação da qualidade das maçãs. Aparentemente, ações contínuas ("ciclo virtuoso") de treinamento e cooperação entre todos os agentes das cadeias de suprimento de frutas e verduras frescas, associadas a avanços tecnológicos, são imprescindíveis para minimizar as perdas pós-colheita da qualidade e da produção (COLLINS, 2010; McEVILLY; FISCHER, 2010). Práticas diferenciadas de manejo das frutas e verduras adotadas em lojas especializadas que minimizam a deterioração nesses pontos estão normalmente associadas a maior sensibilidade ("compaixão") dos proprietários para oferecer produtos de valor que satisfaçam os consumidores (COLLINS, 2010; FISCHER, 2010).

A incidência de maçãs 'Gala' e 'Fuji' com sintomas de podridões, nas gôndolas dos supermercados, aumentou ao longo do ano, especialmente a partir do mês de junho (Figura 3). Entre junho e dezembro de 2010, a incidência de maçãs com podridões nos supermercados foi máxima para 'Fuji' e mínima para 'Red Delicious' $(p<0,05)$. Em 'Fuji', a incidência de podridões variou de 12 a $20 \%$ entre novembro de 2010 e janeiro de 2011 , enquanto a incidência de maçãs 'Red Delicious' com sintomas de podridões manteve-se estável, abaixo de $5 \%$ ao longo de todo o ano. A menor $(\mathrm{p}<0,05)$ incidência de podridões em maçãs 'Gala' que em 'Fuji' (Figura 3) está de acordo com as observações de que maçãs ‘Fuji’ são mais suscetíveis a podridões que maçãs 'Gala' (SANHUEZA et al., 2006).

Alta temperatura de estocagem dos frutos nos entrepostos e supermercados contribui para o aumento de sua categoria (redução da qualidade) antes de serem consumidas, considerando que ela é o fator que mais afeta as reações biológicas relacionadas à maturação e senescência dos frutos e ao crescimento de fungos patogênicos (JOHNSTON, et al., 2001; KADER,2005). Por outro lado, considerando que a maioria dos supermercados, mesmo de países desenvolvidos como Japão, usa uma única câmara de estocagem para frutas e verduras de diferentes espécies, as baixas temperaturas nessas câmaras favorecem a deterioração dos produtos suscetíveis a danos por frio (AKINAGA et al., 2010). Neste estudo, constatou-se que a temperatura média dos frutos na gôndola dos supermercados foi sempre superior a $17^{\circ} \mathrm{C}$ (Figura 5). Ao longo dos 11 meses de amostragem, encontrou-se maçãs 'Gala' e 'Fuji' expostas em ambiente refrigerado em apenas $12,5 \%$ dos expositores analisados. Pesquisa desenvolvida nos Estados Unidos comprovou que maçãs transportadas em contêineres refrigerados apresentam, nos mercados distantes do local de produção, maior qualidade que aquelas transportadas em contêineres não refrigerados (KUPFERMAN, 2010).

O tempo médio entre a data de embalagem dos frutos e sua exposição nas gôndolas dos mercados foi de 28; 17 e 55 dias para maçãs 'Gala', 'Fuji' e 'Red Delicious', respectivamente (Figura 5). Os maiores intervalos entre a data de empacotamento e a exposição dos frutos nas gôndolas dos mercados foram de 58 dias em novembro, para a 'Gala';45 dias em abril, para a 'Fuji', e 95 dias em novembro, para a 'Red Delicious'. Esse resultado é particularmente importante porque, em nenhum dos supermercados onde foi possível anotar a temperatura da sala de estocagem, a temperatura do ambiente foi inferior a $15^{\circ} \mathrm{C}$ (dados não apresentados). Esse longo período entre a data de expedição a partir dos parques de armazenagem e a data de comercialização, associado a temperaturas inadequadas nas salas de estocagem dos supermercados e eventualmente dos entrepostos, certamente, favorecem a depreciação dos frutos após o empacotamento.

Vários fatores podem contribuir para o alto intervalo de tempo entre a data de embalagem dos frutos e a data de exposição nas gôndolas. Destacase a distância entre o local de produção e os pontos de comercialização dos frutos e, principalmente, a estocagem de maçãs por mercados atacadistas ou grandes redes de supermercados que possuem entrepostos de distribuição para as lojas. A compra de grandes quantidades de frutas em uma só vez pelos atacadistas e grandes redes de supermercado, possivelmente, favorece a obtenção de baixos preços, enquanto a manutenção de 'estoque regulador' reduz a pressão de comprar a qualquer preço para evitar descontinuidade da exposição de frutas nas lojas. Adicionalmente, algumas vezes, maçãs de determinada cultivar, categoria e tamanho podem permanecer empacotadas no local de produção, nos parques de armazenagem e no empacotamento quando há desequilíbrio entre a oferta e a demanda do mercado por maçãs daquela cultivar ou categoria.

A incidência de maçãs com sintomas de escaldadura superficial nos supermercados foi observada para a cultivar 'Fuji' e, excepcionalmente, no mês de outubro para a cultivar 'Red Delicious'. Em maçãs 'Fuji', a incidência de escaldadura superficial ocorreu a partir de setembro, sendo máxima em janeiro (Figura 4). 


\section{Qualidade em função da região de comercialização:}

A firmeza de polpa média de maçãs 'Fuji' não foi influenciada pela região de comercialização (Figura 6). No entanto, maçãs 'Gala' comercializadas em Belo Horizonte apresentaram da polpa firmeza média similar à de São Paulo e significativamente superior àquelas comercializadas em Curitiba, Rio de Janeiro e Recife. A categoria das maçãs expostas nas gôndolas dos supermercados variou em função da região de comercialização, dependendo da cultivar. A categoria de maçãs 'Galas' expostas nas gôndolas foi máxima (mínima qualidade) nos supermercados de Curitiba e mínima (máxima qualidade) nos supermercados do Rio de Janeiro. Maçãs 'Fuji' expostas nas gôndolas dos supermercados do Rio de Janeiro, São Paulo e Belo Horizonte apresentaram menor categoria (maior qualidade) que aquelas de Curitiba e Recife. A categoria de maçãs 'Red Delicious' não variou significativamente em função da cidade. A comparação da categoria descrita nas embalagens e a categoria determinada pala análise dos frutos da gôndola, por cidade, também evidenciam que há perda da qualidade (aumento da categoria) entre o ponto de expedição das maçãs nos parques de armazenagem e o empacotamento, e o momento de exposição comercial aos consumidores. A incidência de podridões, para cada uma das cultivares, não foi influenciada pela região de comercialização (Figura 6). A incidência média de escurecimento de polpa de maçãs 'Gala' comercializadas em Curitiba foi significativamente superior àquelas comercializadas em Belo Horizonte, São Paulo, Rio de Janeiro e Recife (Figura 6).

\section{Preço:}

Os preços de venda das maçãs nos supermercados mudaram gradativamente ao longo do ano, atingindo valores máximos nos meses de novembro e dezembro para 'Gala' e de janeiro a março para 'Fuji' (Figura 2). Os preços de maçãs 'Red Delicious' variaram menos que os de 'Gala' e 'Fuji' ao longo do ano e foram máximos nos meses de janeiro a abril. No entanto, a Categoria das maçãs das três cultivares dispostas nas gôndolas aumentou levemente no período de março a dezembro e janeiro, significando que a qualidade externa das maçãs foi levemente reduzida ao longo desse período (Figura 2). Esse fato de os preços aumentarem nos meses pós-colheita (entressafra) sem simultaneidade com o aumento da qualidade (redução da Categoria) das maçãs nas gôndolas indica que os preços foram mais relacionados à sazonalidade da pressão de oferta que à qualidade dos frutos.
O preço das maçãs foi máximo nos supermercados de Recife e São Paulo e mínimos nos supermercados de Curitiba e Belo Horizonte para as três cultivares (Figura 6). No entanto, esse padrão de variação do preço em função da cidade não se repetiu para a variação da qualidade externa (Categoria) ou interna (firmeza da polpa) (Figura 6).

No período de julho a dezembro, a Categoria de maçãs 'Gala' descritas nas etiquetas das embalagens diminuiu levemente (a qualidade aumentou) enquanto a Categoria das maçãs 'Gala' definida pela análise dos frutos dispostos na gôndola aumentou levemente (a qualidade diminuiu) (Figura 2). Isso evidencia que há depreciação da qualidade no período entre o empacotamento e a exposição aos consumidores, não acompanhada de redução de preços. Assim, a ausência de correlação entre preço e categoria dos frutos nas gôndolas possivelmente está relacionada, pelo menos em parte, ao aumento da categoria (redução da qualidade) das maçãs após a expedição no ponto de empacotamento, especialmente devido à alta incidência de danos mecânicos e podridões (Figura 3).

Interessante notar que, nos meses de abril, maio, junho, setembro e outubro, houve correlação significativa $(\mathrm{p}<0,05)$ entre preço e categoria para maçãs 'Fuji', e excepcionalmente no mês de outubro, para maçãs 'Red Delicious' (Tabela 2). Também houve correlação significativa entre preço e incidência de cor vermelha para maçãs ' $G a l a$ ' $(r=-$ $0,30 ; \mathrm{p}<0,05)$ e 'Fuji' $(\mathrm{r}=-0,25 ; \mathrm{p}<0,05)$, para análise dos dados de todos os meses em conjunto.

Curiosamente, os preços de venda das maçãs 'Gala' e 'Fuji' aos consumidores, aplicados nos supermercados, variaram ao longo do ano, precisamente com a mesma tendência da variação dos preços aplicados pelo setor produtivo das maçãs (Figura 2), significando que os preços aplicados nos supermercados se relacionam aos preços de venda pelos empacotadores. O preço cobrado pelos produtores (empacotadores) normalmente varia em função da categoria, sendo os maiores preços obtidos na Categoria 1. Os dados de variação de preços aplicados pelos produtores em função da categoria e do mês (Figura 2) demonstram que ambos, qualidade (Categoria) e período de comercialização, influenciam na definição de preço, embora a sazonalidade da oferta, aparentemente, influencie mais que a qualidade. Assim, a ausência de correlação entre preço e categoria dos frutos nas gôndolas, observada neste estudo, não significa necessariamente que os preços de venda das maçãs pelos produtores (empacotadores) não sejam relacionados à categoria. Estudo com amostragem 
maior que a de 20 supermercados, num único mês, poderia gerar informação mais segura sobre a disposição de os consumidores pagarem por qualidade.

Os dados do presente estudo também mostram a grande diferença dos preços aplicados na venda ao atacado e nos supermercados, e na venda aos consumidores (Figura 2). Aparentemente, a manutenção dessa diferença de preços aplicados pelo setor produtivo e pelo varejo está relacionada, em parte, à relação excessivamente alta entre número de empresas de venda de maçãs no setor produtivo e o número de empresas compradoras de maçãs no atacado e varejo (PÉRÈS, 2009), além dos elevados custos relacionados ao transporte, distribuição, serviços de comercialização e às perdas por deterioração durante essas fases.

Segundo Harker et al. (2008), a escolha dos consumidores por maçãs baseia-se principalmente na relação preço e qualidade, sendo que a qualidade é o fator motivador para $80 \%$ das pessoas com hábito regular de consumo de maçãs, quando os preços estão dentro do esperado. Contudo, quando o preço de maçãs aumenta no mercado, os consumidores podem substituir a compra de maçãs por outras frutas, especialmente se elas não tiverem alta qualidade (HARKER et al., 2003). Isto evidencia que a competição no mercado inter-cadeias produtivas de frutas possivelmente é tão grande quanto a competição intracadeia produtiva de frutas.

O aumento da qualidade $\mathrm{e} o$ apelo aos valores nutricionais das frutas são algumas das importantes estratégias para o aumento do consumo de frutas e a competição frente às cadeias produtivas de produtos industrializados e guloseimas (HARKER et al., 2003). A decisão de consumidores escolherem frutas é marcadamente influenciada pelo fato de ser um produto saudável. Contudo, se o sabor não for bom, a compra não é repetida, pelo menos por determinado período (HARKER et al., 2003). Isto evidencia o enorme papel da qualidade interna (sabor e textura) dos frutos para a manutenção e o aumento do consumo de maçã.

TABELA 1- Categoria na gôndola de maçãs 'Gala', 'Fuji' e 'Red Delicious' ao longo do ano. A categoria (escala 1 a 3 ) foi determinada mensalmente para cada cultivar pela análise de uma amostra de 22 frutos por supermercado (4 por cidade) e cidade $(5)(n=20)$.

\begin{tabular}{llrc}
\hline \multirow{2}{*}{ Mês de análise } & \multicolumn{3}{c}{ Categoria na Gôndola (Escala 1 a 3) } \\
\cline { 2 - 4 } Março & 'Gala' & 'Fuji' & 'Red Delicious' \\
Abril & $1,76 \mathrm{ab}^{1}$ & $1,85 \mathrm{a}$ & $1,56 \mathrm{~b}$ \\
Maio & $1,75 \mathrm{a}$ & $1,80 \mathrm{a}$ & $1,66 \mathrm{a}$ \\
Junho & $1,64 \mathrm{ab}$ & $1,73 \mathrm{a}$ & $1,44 \mathrm{~b}$ \\
Julho & $1,70 \mathrm{a}$ & $1,72 \mathrm{a}$ & $1,55 \mathrm{a}$ \\
Agosto & $1,71 \mathrm{a}$ & $1,92 \mathrm{a}$ & $1,64 \mathrm{a}$ \\
Setembro & $1,80 \mathrm{a}$ & $1,93 \mathrm{a}$ & $1,77 \mathrm{a}$ \\
Outubro & $1,70 \mathrm{a}$ & $1,99 \mathrm{a}$ & $1,72 \mathrm{a}$ \\
Novembro & $1,91 \mathrm{ab}$ & $2,07 \mathrm{a}$ & $1,60 \mathrm{~b}$ \\
Dezembro & $1,73 \mathrm{~b}$ & $2,17 \mathrm{a}$ & $1,79 \mathrm{~b}$ \\
Janeiro & $1,84 \mathrm{a}$ & $1,98 \mathrm{a}$ & $1,71 \mathrm{a}$ \\
\hline${ }^{1}$ Médias seguidas pela mesma letra na linha não diferem entre si, pelo teste de Tukey $(\mathrm{p}<0,05)$.
\end{tabular}

TABELA 2- Índice de correlação entre preço (R\$) e categoria (escala 1 a 3) de maçãs 'Gala', 'Fuji' e 'Red Delicious' em função do mês. O preço e a categoria foram determinados mensalmente para cada cultivar pela análise de uma amostra de 22 frutos por supermercado ( 4 por cidade) e cidade (5) ( $\mathrm{n}=20)$.

\begin{tabular}{lllc}
\hline \multirow{2}{*}{ Mês de análise } & \multicolumn{3}{c}{ Cultivar } \\
\cline { 2 - 4 } Março & 'Gala' & 'Fuji & 'Red Delicious' \\
Abril & $0,06 \mathrm{~ns}^{1}$ & $-0,50 \mathrm{~ns}$ & $-0,15 \mathrm{~ns}$ \\
Maio & $0,05 \mathrm{~ns}$ & $-0,59^{*}$ & $0,20 \mathrm{~ns}$ \\
Junho & $0,33 \mathrm{~ns}$ & $-0,49^{*}$ & $0,01 \mathrm{~ns}$ \\
Julho & $-0,17 \mathrm{~ns}$ & $-0,51^{*}$ & $0,02 \mathrm{~ns}$ \\
Agosto & $-0,16 \mathrm{~ns}$ & $-0,02 \mathrm{~ns}$ & $0,09 \mathrm{~ns}$ \\
Setembro & $-0,04 \mathrm{~ns}$ & $-0,25 \mathrm{~ns}$ & $-0,15 \mathrm{~ns}$ \\
Outubro & $-0,15 \mathrm{~ns}$ & $-0,74^{*}$ & $-0,10 \mathrm{~ns}$ \\
Novembro & $-0,26 \mathrm{~ns}$ & $-0,55^{*}$ & $-0,45^{*}$ \\
Dezembro & $-0,06 \mathrm{~ns}$ & $-0,44 \mathrm{~ns}$ & $-0,02 \mathrm{~ns}$ \\
Janeiro & $-0,31 \mathrm{~ns}$ & $-0,37 \mathrm{~ns}$ & $0,18 \mathrm{~ns}$ \\
\hline
\end{tabular}

${ }^{1}(*)$ significância $(\mathrm{p}<0,05)$ pelo teste de Person Product Moment. ns - não significativo. 


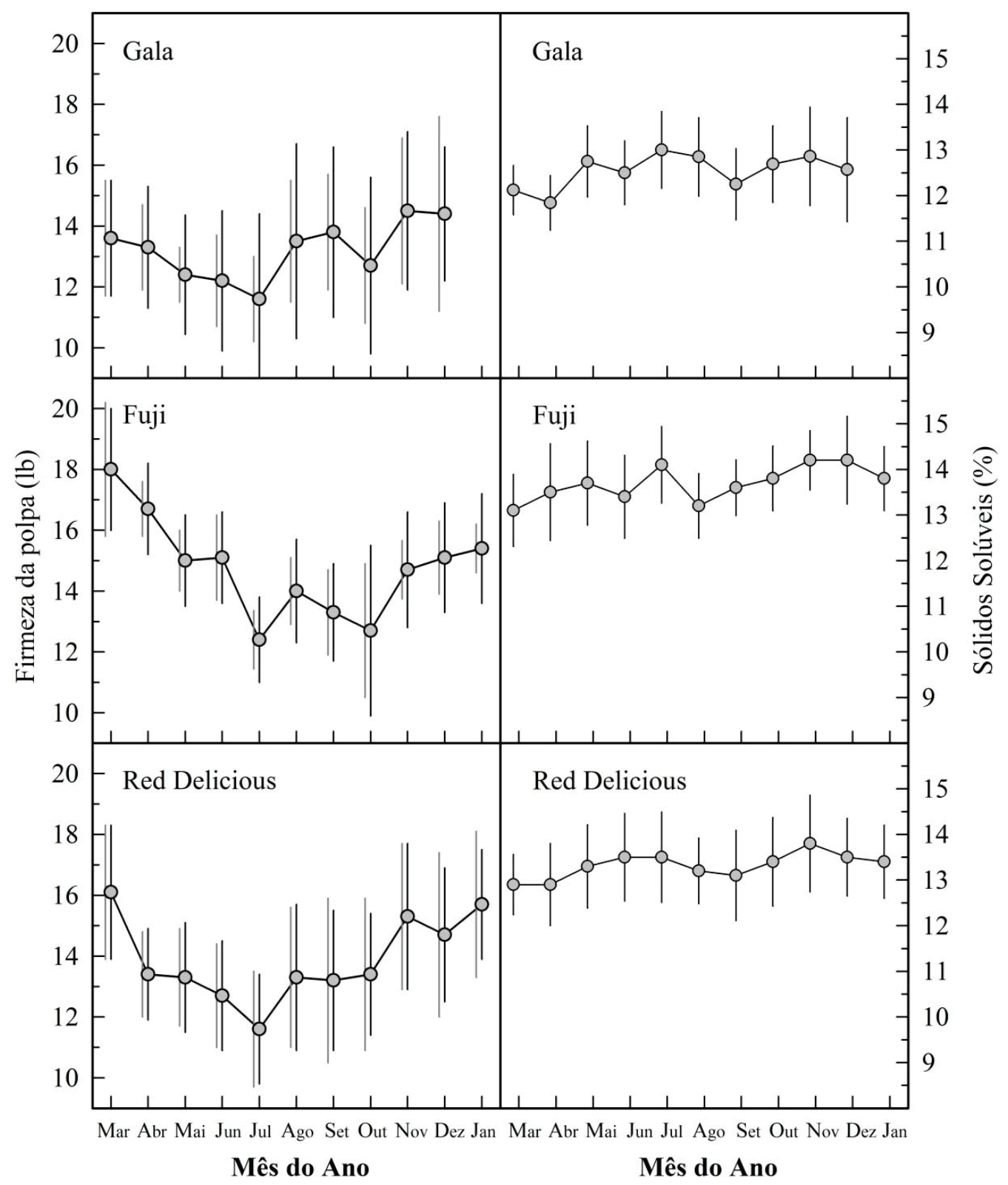

FIGURA 1- Firmeza da polpa e teor de sólidos solúveis totais de maçãs 'Gala', 'Fuji' e 'Red Delicious' ao longo do ano. As barras verticais de cor preta nos gráficos de firmeza e sólidos solúveis indicam o desvio entre supermercados $(n=20)$. As barras verticais de cor cinza no gráfico de firmeza indicam o desvio-padrão médio entre frutos $(\mathrm{n}=22)$. 


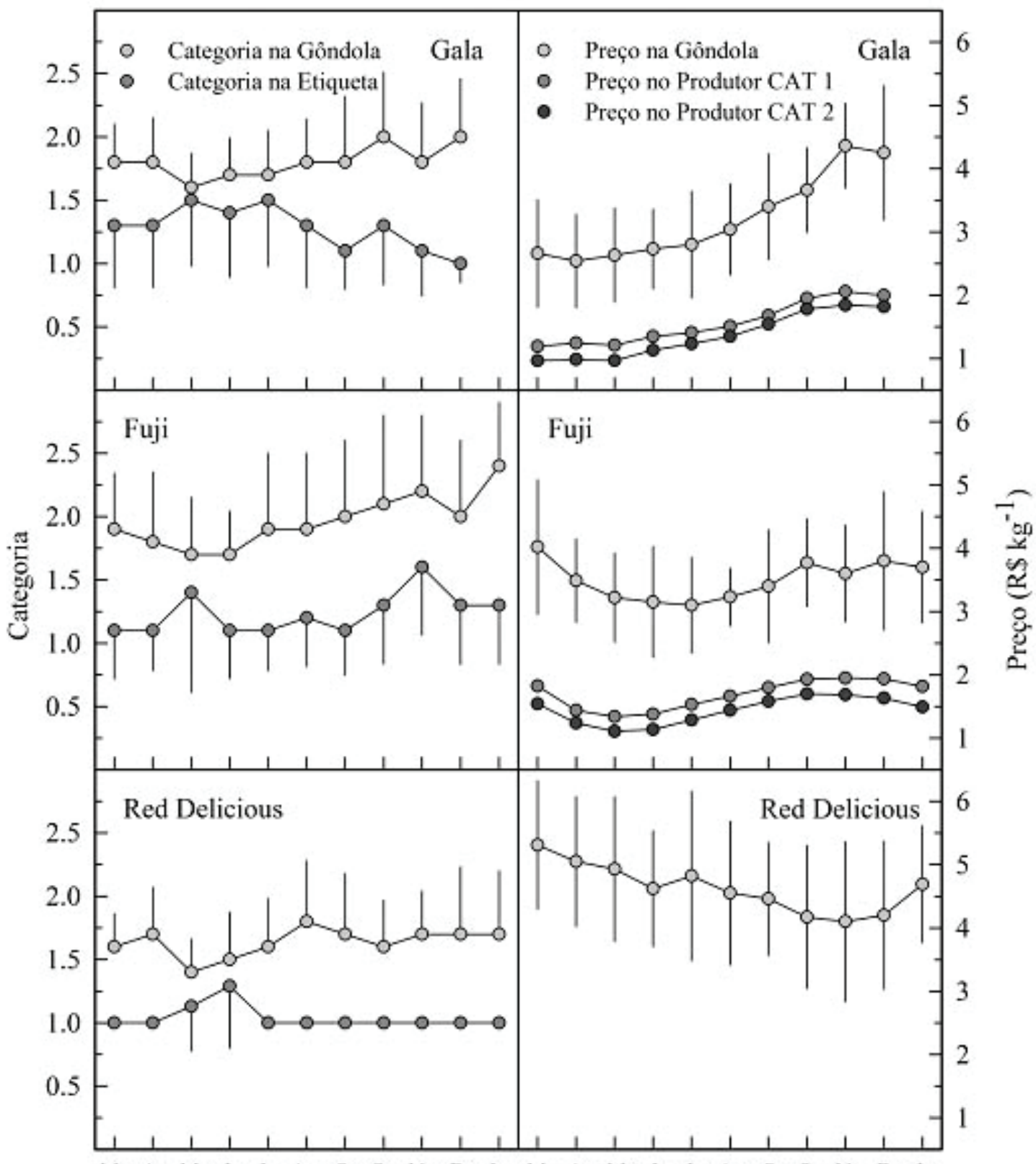

Mar Abre Mai Jun Jul Ago Set Out Nov Dez Jan Mar Abr Mai Jun Jul Ago Set Out Nov Dez Jan

Mês do Ano

Mês do Ano

FIGURA 2- Categoria (escala 1 a 3) e preço de maçãs 'Gala', 'Fuji' e 'Red Delicious' ao longo do ano. A categoria na gôndola foi determinada pela análise de uma amostra dos frutos. A categoria etiqueta foi obtida pela análise das embalagens de maçãs presentes na câmara de estocagem do supermercado. O preço na gôndola representa o valor anunciado na gôndola, enquanto o preço do produtor representa o valor médio de venda aplicado pelas empresas da Associação Brasileira de Produtores de Maçãs. As barras verticais indicam o desvio-padrão entre supermercados (4 por cidade) e cidades (5) $(n=20)$. 


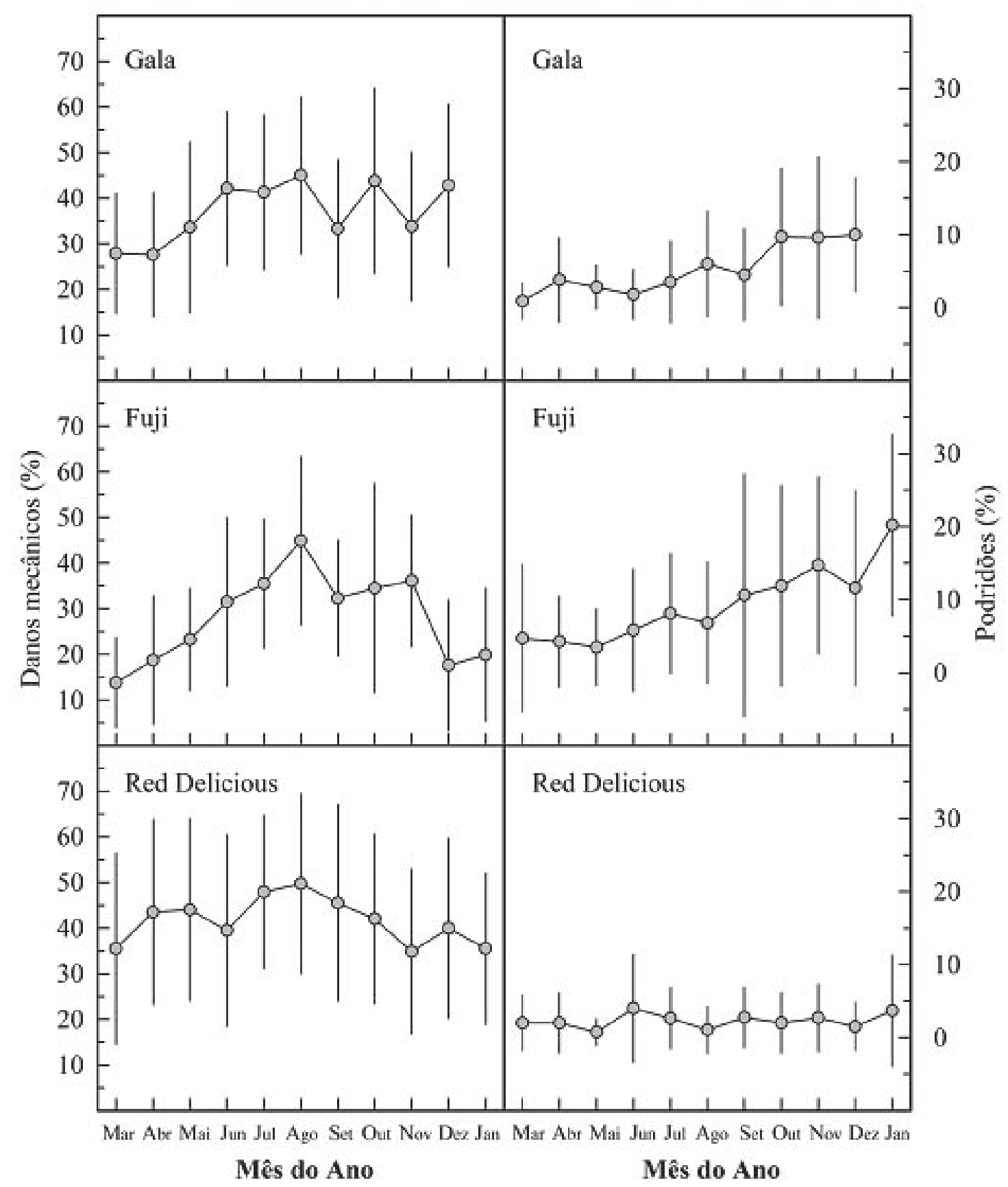

FIGURA 3- Incidência de maçãs 'Gala', 'Fuji' e 'Red Delicious' com danos mecânicos e podridões ao longo do ano. As barras verticais indicam o desvio-padrão entre supermercados (4 por cidade) e cidades $(5)(n=20)$. 


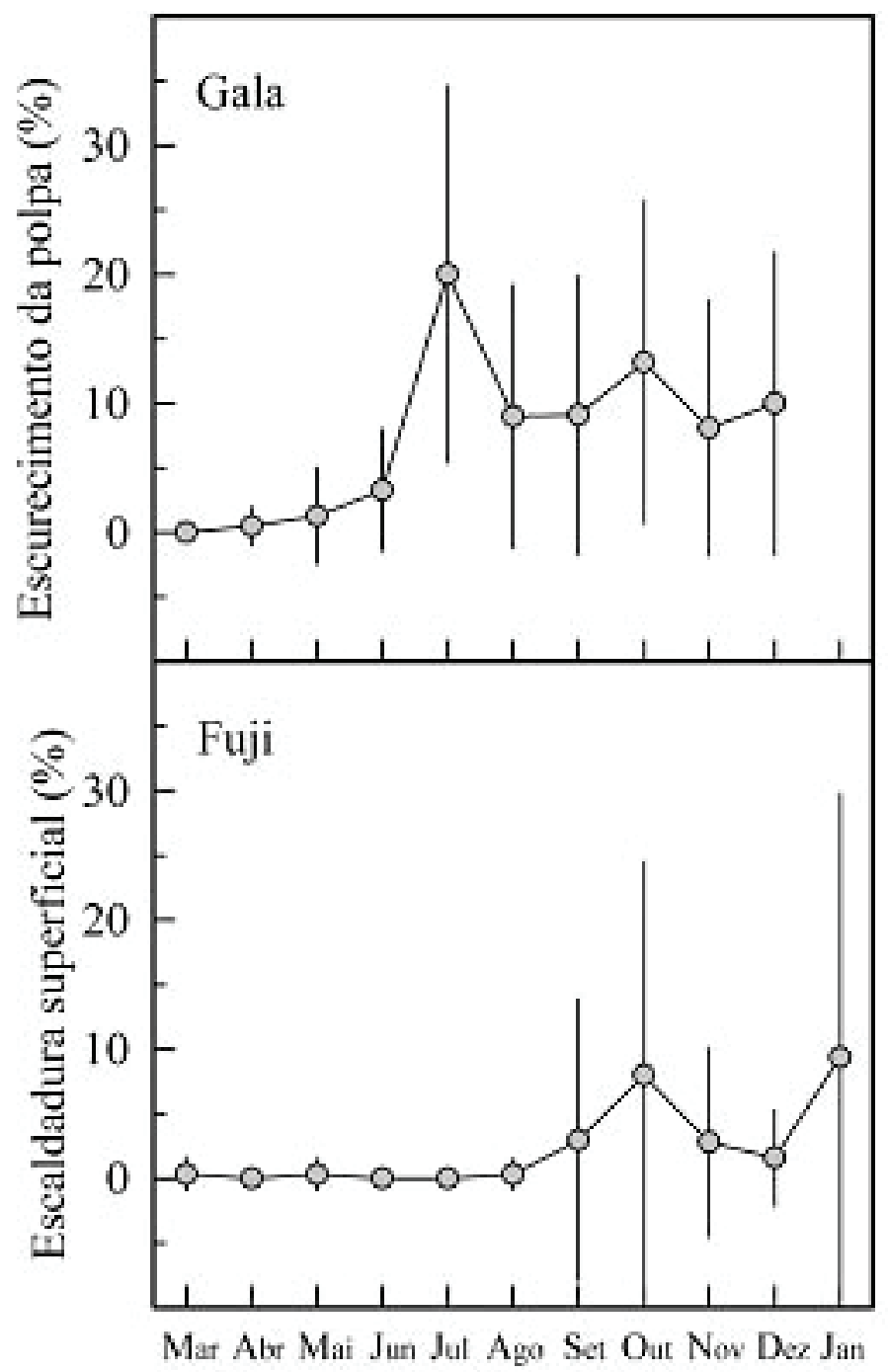

Mês do Ano

FIGURA 4- Incidência de maçãs 'Gala' e 'Fuji' com escurecimento da polpa e escaldadura superficial. As barras verticais indicam o desvio-padrão entre supermercados (4 por cidade) e cidades (5) $(\mathrm{n}=20)$. 


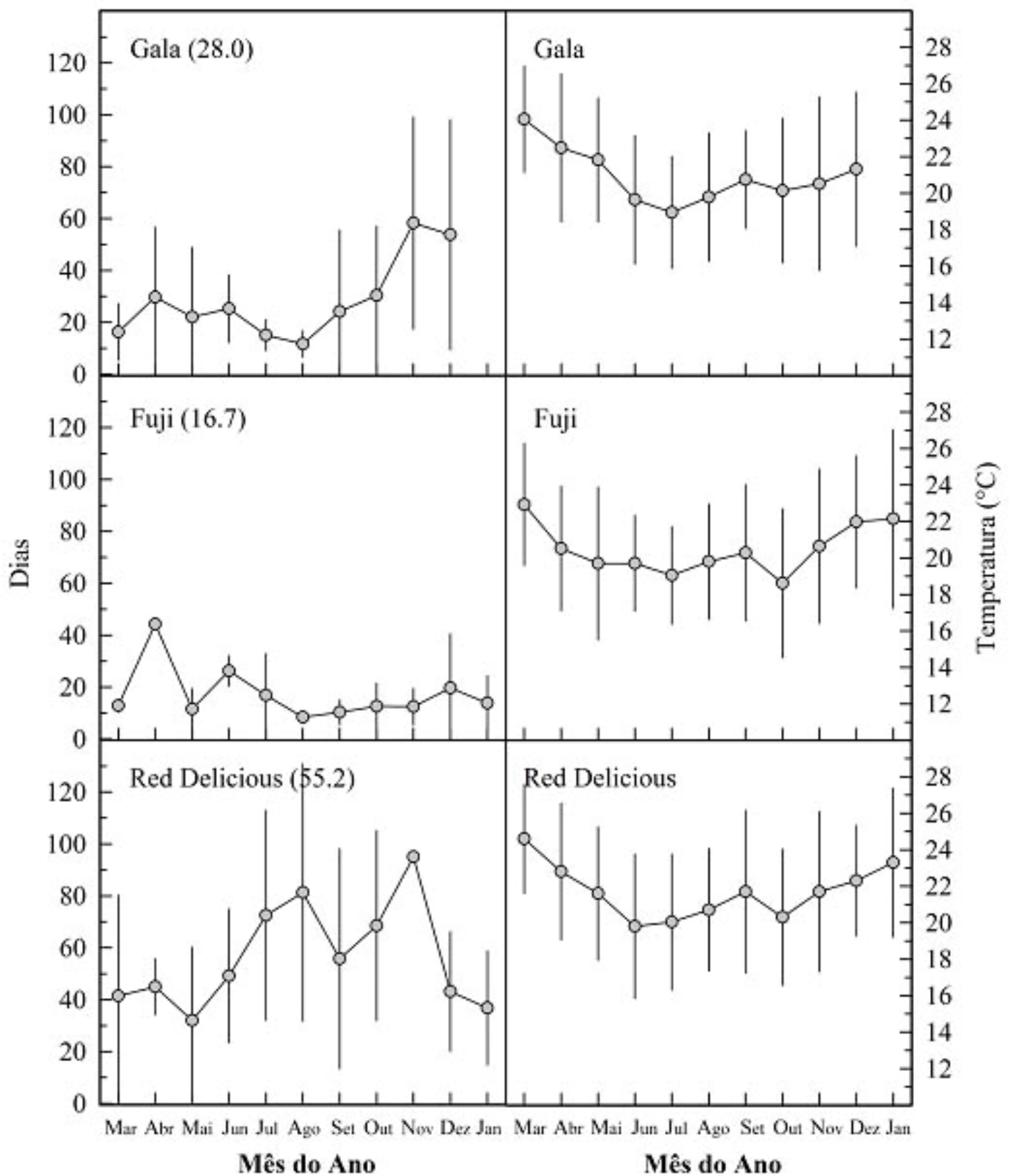

FIGURA 5-Temperatura da polpa de maçãs 'Gala', 'Fuji' e 'Red Delicious' na Gôndola e tempo (dias) entre a data de empacotamento das maçãs e a data de análise das embalagens de maçãs nos supermercados. Valores entre parênteses no interior dos gráficos representam o tempo (dias) médio entre a data de empacotamento das maçãs e a data de análise das embalagens de maçãs nos supermercados (média dos 11 meses). As barras verticais indicam o desvio-padrão entre supermercados ( 4 por cidade) e cidades $(5)(\mathrm{n}=20)$. 


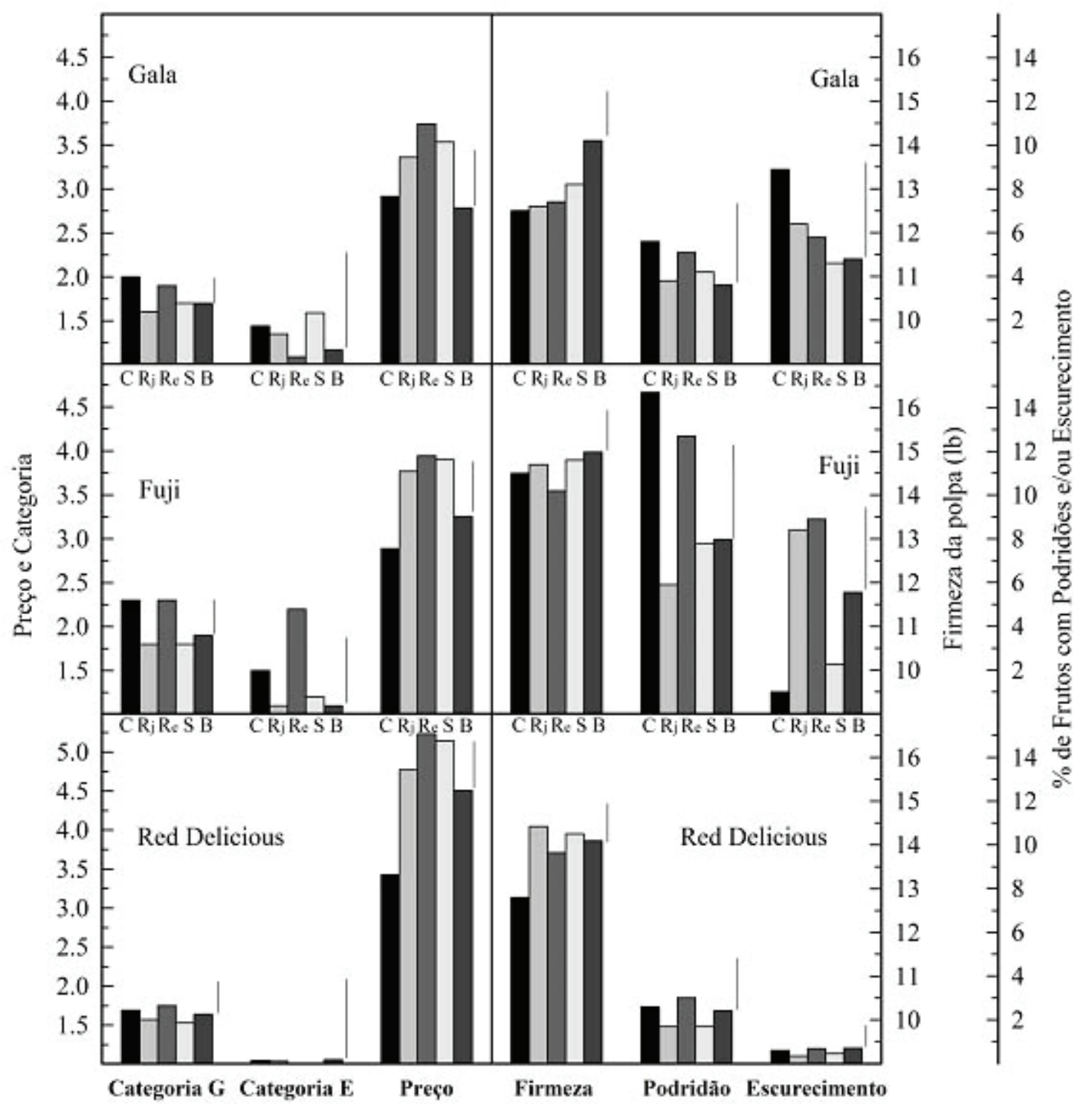

FIGURA 6-Categoria (escala 1 a 3), preço, firmeza da polpa e incidência (\%) de maçãs 'Gala', 'Fuji' e 'Red Delicious' com distúrbios (Podridão e Escurecimento) em função da cidade (C: Curitiba, Re: Recife, S: São Paulo, B: Belo Horizonte, Rj: Rio de Janeiro). A categoria na gôndola (Categoria G) foi determinada pela análise de uma amostra dos frutos. A categoria etiqueta (Categoria E) foi obtida pela análise das embalagens de maçãs presentes na câmara de estocagem do supermercado. O preço na gôndola representa o valor anunciado na gôndola. As barras verticais indicam o desvio- padrão entre supermercados (4 por cidade) e meses (11) ( $\mathrm{n}=44)$. 


\section{CONCLUSÕES}

Grande parte das maçãs expostas nos supermercados apresenta firmeza da polpa inferior a $14 \mathrm{lb}$, na maioria dos meses do ano, especialmente aquelas das cultivares Gala e Red Delicious.

A baixa qualidade externa das maçãs expostas nos supermercados está associada à alta incidência de danos mecânicos e podridões.

Variação sazonal da pressão de oferta de maçãs no mercado prepondera à variação da qualidade das maçãs nas gôndolas e na formulação de seu preço aos consumidores.

O preço das maçãs varia entre as regiões de comercialização de forma similar para as três cultivares.

A qualidade das maçãs varia entre regiões de comercialização, dependendo da cultivar e do atributo de qualidade.

O tempo entre a data de embalagem das maçãs e de sua exposição nos supermercados é de 17; 28 e 55 dias para as maçãs 'Gala', 'Fuji' e 'Red Delicious', respectivamente.

Maçãs são expostas a temperaturas ambientes (não refrigerada) em $88 \%$ dos supermercados analisados ao longo de 11 meses.

\section{AGRADECIMENTOS}

O presente estudo foi financiado pela AgroFresh Inc., Dow AgroSciences.

\section{REFERÊNCIAS}

AKINAGA, T.; KAWASAKI, S.; SHIMA, H. Quality management of fresh fruit and vegetables at a supermarket chain in japan. Acta Horticulturae, The Hague, n. 880, p.111-116. 2010.

ARGENTA, L. C.; DENARDI, F. Perdas físicoquímicas mensais de maçãs 'Gala' e 'Fuji' durante a armazenagem em atmosfera controlada e frio convencional. Revista Brasileira de Fruticultura, Jaboticabal, v.16, n.3, p.111-118, 1994.

BATT, P.J.; SADLER, C. Consumer attitudes towards the labeling of apples. Food Australia, North Sidney, v.50, p.449-450, 1998.

BRASIL. Ministério da Agricultura, Pecuária e Abastecimento. Regulamento técnico de identidade e qualidade da maçã. Brasília, 2006. 9p. (Instrução Normativa, 5).
CNA - Confederação da Agricultura e Pecuária do Brasil. Hábitos de consumo de frutas, legumes e verduras no Brasil (FLVs). Brasília, 2011. Disponível em: $\leq$ http://arquivopdf.sebrae.com.br/ setor/horticultura $>$.

COLLINS, R. Postharvest science and value chain management: Using the virtuous value cycle to define common ground. Acta Horticulturae, The Hague, n. 880, p.67-74. 2010.

FISCHER, C. Opportunities for innovation in specialised fruit and vegetable retailing: results from an auckland greengrocer survey. Acta Horticulturae, The Hague, n. 880, p.91-97. 2010.

GALLARDO, R.K.; KUPFERMAN, E.; COLONNA, A. Willingness-to-pay for Optimal Anjou Pear Quality. HortScience, New York, v.46, n.3, p.452456, 2011.

HARKER, F.R.; GUNSON, F.A.; JAEGER, S.R. The case of fruit quality: an interpretative review of consumer attitudes and preferences for apples. Postharvest Biology and Technology, Amsterdam, v.28, n.3, p.333-347, 2003.

HARKER, F.R.; KUPFERMAN, E.M.; MARIN, A.B.; GUNSON, F.A.; TRIGGS, C.M. Eating quality standards for apples based on consumer preferences. Postharvest Biology and Technology, Amsterdan, v.50, n.1, p.70-78, 2008.

HARKER, F.R.; MAINDONALD, J.; MURRAY, S.H.; GUNSON, F.A.; WALKER, S.B. Sensory interpretation of instrumental measurements 1: texture of apple fruit. Postharvest Biology and Technology, Amsterdam, v.24, n.3, p.225-239, 2002.

JOHNSTON, J.W.; HEWETT, E.W.; HERTOG, M.L.A.T.M.; HARKER, F.R. Temperature induces differential softening responses in apples cultivars. Postharvest Biology and Technology, Amsterdan, v.23, n.3, p.185-196, 2001.

KADER, A.A. Increasing food availability by reducing postharvest losses of fresh produce. Acta Horticulturae, The Hague, n.682, p.2.169-2.175. 2005 .

KUPFERMAN, E.M. Keeping the customer satisfied. Washington: Good Fruit Growers, 2010. p.28-29. 
McEVILLY, G.; FISCHER, C. Supply chain workshop: summary of key success factors for horticultural supply chains and the supply chain of the future. Acta Horticulturae, The Hague, n. 880, p. $145-150.2010$.

MITSUHASHI-GONZALEZ, K.M.; PITTS, J.; FELLMAN, J. K.; CURRY, E. A.; CLARY, C. D. Bruising profile of fresh apples associated with tissue type and structure. Applied Engineering in Agriculture. Michigan, v.26, n.3, p.509-517, 2010.

PÉRÈS, P.N. O mercado mundial e nacional de maçã. In: ENCONTRO NACIONAL SOBRE FRUTICULTURA DE CLIMA TEMPERADO, 11., 2009, Fraiburgo. Palestras...Caçador: Epagri, 2009. p.117-126.

PETRI，J.L.; LEITE，G.B.; COUTO, M.; FRANCESCATTO, P. Avanços na cultura da macieira no Brasil. Revista Brasileira de Fruticultura. Jaboticabal, v.33, p.48-56. 2011. Número especial.
SANHUEZA, R.M.V; MAFFIOLETTI, M.; COMPARIM, C.C.; KRASNIAK, J.; BOGO, A.; ARCARI, R. Características e controle da podridão "olho de boi" nas maçãs do Sul do Brasil. Bento Gonçalves: EMBRAPA-CNPUV, 2006. 12p. (Circular Técnica, 66)

VARELA, P.; SALVADOR, A.; FIZMAN, S. Shelflife estimation of 'Fuji' apples: Sensory characteristics and consumer acceptability. Postharvest Biology and Technology, Amsterdam, v.38, n.1, p.18-24, 2005.

ZEEBROECK, M.V.; LINDEN, V.V.; RAMON, H.; BAERDEMAEKER, J.; NICOLAI, B.M.; TIJSKENS, E. Impact damage of apples during transport and handling. Postharvest Biology and Technology, Amsterdam, v.45, n.2, p. 157-167. 2007. 